\title{
PARTICIPAÇÃO CIDADÃ NA AGENDA DE POLÍTICAS PÚBLICAS: UM OLHAR DESDE OS DIREITOS HUMANOS
}

\author{
Jadir Zaro ${ }^{1}$ \\ Micheli Capuano Irigaray ${ }^{2}$
}

\begin{abstract}
RESUMO: A participação cidadã na agenda de políticas públicas pode ampliar os espaços democráticos, na perspectiva do reconhecimento e efetivação dos direitos humanos. A problemática da presente pesquisa busca refletir as possibilidades da democratização de políticas públicas. No primeiro capítulo analisar as políticas públicas para além de uma abordagem sequencial; no segundo refletir sobre a participação cidadã para a construção de uma ordem democrática; e no terceiro verificar a inserção do terceiro setor na construção de uma nova ordem de políticas públicas. Metodologicamente, adotou-se uma abordagem sistêmica, como procedimento a pesquisa bibliográfica e documental.
\end{abstract}

Palavras-Chaves: Participação; Cidadã; Democracia; Políticas Públicas; Direitos Humanos.

\section{CITIZEN PARTICIPATION IN THE PUBLIC POLICY AGENDA: A LOOK AT HUMAN RIGHTS}

\begin{abstract}
Citizen participation in the public policy agenda can broaden democratic spaces, with a view to the recognition and implementation of human rights. The problem of the present research seeks to reflect the possibilities of the democratization of public policies. In the first chapter analyze public policies beyond a sequential approach; in the second, reflect on citizen participation for the construction of a democratic order; and in the third to verify the insertion of the third sector in the construction of a new order of public policies. Methodologically, a systemic approach was adopted, as a bibliographic and documentary research procedure.
\end{abstract}

Keywords: Citizen; Participation; Democracy; Public Policy; Human Rights.

\footnotetext{
${ }^{1}$ Doutorando e mestre em Direito pelo Programa de Pós-Graduação em Direito da Universidade de Santa Cruz do Sul/UNISC. Graduado em Direito pela UCDB. Graduado em Filosofia pelo UNIFRA. E-mail: jadirzaro@pallottipoa.com.br

${ }^{2}$ Doutoranda em Direito Universidade de Santa Cruz do Sul - UNISC, integrante Grupo de Estudos Constitucionalismo Contemporâneo, Mestre em Direito -UFSM, Especialização em Direito Civil, Constitucional e Ambiental - URCAMP. E-mail:capgaray @ brturbo.com.br
} 


\section{INTRODUÇÃO}

A sociedade contemporânea acentua interesse maior pelas políticas públicas, acreditase, motivado pela intervenção constante do estado na iniciativa privada e pelo crescimento da análise dos resultados da ação política em desenvolvimento. Palavras como solidariedade, participação e cooperação, são compreendidas e aceitas por grande parte da sociedade e percebidas como uma forma de resgate da dignidade humana tão massacrada pela sociedade liberal.

Direitos humanos, para serem reais e efetivos, devem estar baseados em políticas públicas que as promovam e uma educação que reconheça o seu valor. O que demonstra a importância de se organizar a sociedade, para que ela não se deixe levar por autoridades alienadas, mercado opressor, interesses do sistema ou de determinada classe, mas reconheça em si um instrumento de transformação.

Nesse contexto observa-se que a participação cidadã, individualmente ou organizada, na agenda de políticas públicas, participando de todo seu processo, pode ampliar os espaços democráticos, na perspectiva do reconhecimento e efetivação dos direitos humanos.

Apresenta-se assim como a problemática da presente pesquisa, a busca sobre os limites e possibilidades da democratização de políticas públicas, para construção de uma nova ordem de direitos humanos?

No primeiro capítulo pretende se analisar as políticas públicas para além de uma abordagem sequencial; no segundo capítulo refletir sobre a participação cidadã em todo processo das políticas públicas, para construção de uma ordem mais democrática; e no terceiro verificar a importância e a inserção do terceiro setor na construção de uma nova ordem de políticas públicas em um olhar desde os direitos humanos para uma sociedade humanizada e humanizadora.

Metodologicamente, adotou-se uma abordagem sistêmica, como procedimento se desenvolve uma pesquisa bibliográfica e documental, como técnica a construção de fichamentos, debates e resumos.

$\mathrm{Na}$ busca da construção de uma sociedade cada vez mais humanizada, destaca-se a importância da participação e cooperação consciente, formada e formativa da comunidade, no reconhecimento dos direitos humanos aplicados e defendidos pelos diversos órgãos públicos, associações e o próprio cidadão na sua individualidade. 


\section{ANÁlise de POLÍticas PÚBliCAS: PARA ALÉM DE UMA ABORDAGEM SEQUENCIAL}

Toda política pública tem por referencial a figura do estado e da sociedade, independentemente das suas atuações diretas ou indiretas. Ela parte da noção da existência de um problema, propondo e construindo soluções, através de decisões e ações:

Política pública pode ser definida como um conjunto de decisões e ações de órgãos públicos e organizações da sociedade, dotadas de coerência intencional, que, sob coordenação estatal, destina-se a enfrentar um problema político. Toda política pública constitui uma tentativa de intervenção na realidade social, seja de controle ou de mudança, deflagrada com base na percepção pública de que uma situação indesejada requer intervenção transformadora. (SCHMIDT, 2017, p. 127)

$\mathrm{Na}$ análise de políticas públicas observa-se a necessidade de resposta(s) aos problemas sociais, os quais podem ser merecedores de inserção na agenda governamental, dentro de um sistema político-administrativo para uma situação de realidade social inaceitável. (SUBIRATS, 2012)

A identificação dos sintomas de um problema corresponde ao ponto de partida para se pensar em uma política pública, mesmo que ainda não se tenha uma exata dimensão das causas de um determinado problema coletivo, como também não tenha um consenso por parte dos atores, tanto públicos como privados sobre a definição do mesmo.

Observa-se ainda, que as políticas públicas constituem uma resposta a um problema público que reflete um problema social, o qual se destaca por articulações dos meios de comunicação, de movimentos sociais, partidos políticos, grupos de interesses determinados, levando-se essas questões posteriormente, para o processo democrático de tomada de decisões. Salientando-se assim, que não existe uma resposta institucional linear, mecânica que se possa prever como resultado para um problema coletivo, ela precisa ser construído e implementada. (SUBIRATS, 2012)

Muller e Surel (2002) contribuem para esse aprofundamento na análise de políticas públicas, para além de uma abordagem sequencial, de concepções cognitivas, para além da complexidade própria ao objeto "política pública". Ou ainda uma proposta de complexidade para religar conhecimentos, como uma nova postura do sujeito diante da dinâmica dos sistemas vivos planetários, tendo como principais desafios "realidades" e "problemas" cada vez mais polidisciplinares, transversais, multidimensionais, transnacionais, globais, planetários, repensando assim o pensamento, para solidarizar conhecimentos separados, para uma 
aprendizagem cidadã: comunidade/sociedade, em contribuição com o pensar a análise de políticas públicas.

Nessa perspectiva as políticas públicas e seus elementos constitutivos, perpassam o campo da unificação simples e abstrata entre políticas públicas e o estado, acentua-se que elas não se restringem a esfera estatal, seu campo de abrangência encontra-se numa esfera mais ampliada em relação ao estado:

O conceito políticas públicas remete para a esfera do público e seus problemas. Ou
seja, diz respeito ao plano das questões coletivas, da polis. O público distingue-se do
privado, do particular, do indivíduo e de sua intimidade. Por outro lado o público
distingue-se do estatal: o público é uma dimensão mais ampla, que se desdobra em
estatal e não-estatal. (SCHMIDT, 2008, p. 2311)

O interesse em compreender o que seriam as tais políticas públicas não se restringe à sociedade de uma forma superficial. Nos atuais estudos acadêmicos percebe-se que diversas disciplinas apresentam motivação pelo estudo das políticas públicas, tais como: ciência política, sociologia, economia, antropologia, administração, geografia, ciências sócias, ciências da saúde e direito.

A presente ênfase no interesse pelo estudo das políticas públicas demonstra o surgimento de novas compreensões, conhecimentos e iniciativas, conduzindo a formação de melhores agentes no sistema político atual.

A busca das respostas às políticas públicas, não constituem necessariamente soluções adequadas, o que tem produzido alguns fracassos. Esses podem estar relacionados a fatores como incompetência, falta de vontade dos agentes políticos, a corrupção entre outros. Nessa abordagem destaca-se que uma política compreende um conjunto de ações e participações, e que ações isoladas não fazem uma política, mas em ações interligadas que possam abranger diversas áreas relativas à satisfação de uma determinada demanda política. (SCHMIDT, 2008)

O estudo das políticas públicas pode ter por base sete tipos: estudo do conteúdo das políticas, do processo das políticas, do resultado das políticas, da avaliação, da informação para a elaboração de políticas, da defesa de processos e da defesa de políticas. Sabendo que a teoria deve iluminar a prática. Nesse sentido destacam-se também as três dimensões da política mais aceitas, são: polity: referindo-se a ordem do sistema político; politics: compreendendo o conteúdo concreto da política e policy: definindo o estado em ação sendo os resultado e junção dos anteriores. (SCHMIDT, 2008) 
Ao se comentar a tipologia das políticas públicas, distinguem-se políticas sociais de políticas econômicas, a primeira trata das áreas de atuação, como por exemplo, a saúde, a segunda é mais uma política de fiscalização:

\begin{abstract}
Uma classificação usual das políticas é a que distingue políticas sociais de políticas econômicas ou macroeconômicas. As políticas sociais dizem respeito às áreas ditas "sociais", como saúde, educação, habitação, seguridade e assistência social. As políticas macroeconômicas incluem fundamentalmente a política fiscal e a política monetária, abarcando questões como controle de inflação, a taxa de juros, a taxa de câmbio, os incentivos a determinados setores da economia, o comércio internacional, entre outros. (SCHMIDT, 2008, p. 2313)
\end{abstract}

Outras distinções devem ser lembradas, tais como: políticas distributivas (distribuindo recursos na sociedade ou em determinada região), políticas redistributivas (retirando recursos ou rendas de determinada classe ou região para destinar a outro local), políticas regulatórias (tratando da regulamentação por portarias, decretos etc) e políticas constitutivas ou estruturadoras (definindo procedimentos gerais do governo, desde orçamento até sistema de governo).

Tratando-se dos enfoques teóricos das políticas públicas, destacam-se ainda, as seguintes formas de pensamento: racionalismo (com ênfase ao iluminismo), incrementalismo (criticando o racionalismo) e escolha racional (movidos pela utilidade, atuam nas políticas públicas com interesse particular).

Apesar da amplitude de conceitos e definições apresentadas, a respeito das políticas públicas, para a presente descrição, faz-se adequado e relevante compreender que estas tratamse de políticas de caráter geral que apresentam rumos e linhas de atuação do governo federal, estadual ou municipal em vista do resgate da dignidade humana.

Outro aspecto importante a ser destacado é o processo de construção das políticas públicas, que acontecem ao longo do tempo, apresentando fases específicas, que podem ser assim definidas:

- percepção e definição do problema (se verifica a dificuldade e se apresentam os possíveis problemas);

- inserção na agenda política (é a constituição dos vários problemas e assuntos que o governo deve pensar);

- formulação (onde se define o que vai ser trabalhado e a maneira de como tal situação vai ser desenvolvida);

- condições de implementação (onde se concretiza o formulado e se programa a política); e,

Rev. de Direito Sociais e Políticas Públicas | e-ISSN: 2525-9881 | Porto Alegre | v. 4 | n. 2 | p. 76 - 93 | Jul/Dez. 2018 
- avaliação (se verifica e analisa o foi acertado ou indevidamente feito). (SCHMIDT, 2008)

Ao se acentuar o caráter público das políticas, lembra-se a relação entre política e administração, por muito tempo se definiu que o governo é um ser político eleito e que o administrador público não tem uma relação próxima com o definido por ele. Contudo, o sucesso de determinado governo, plano de governo ou plano de estado, depende dessa relação que deve ser amistosa e de comprometimento.

O sistema político, para ser entendido, deve ser percebido como uma junção de vários componentes: normas, leis, instituições, parlamento, símbolos do governo, partidos, sindicatos, grupos não governamentais, lideres etc. Quando se destaca a junção não se compreende uma simples aglomeração, mas o envolvimento, comprometido com as políticas públicas de um estado.

Nesse sentido o peso de cada agente se dá em função dos recursos que é capaz de mobilizar ou intercambiar. As abordagens teóricas e modelos de análise de toda e qualquer política pública, é elaborada com base em pressupostos teóricos que lhe dão sentido.

Observa-se, pelos conceitos e abordagens referidas, que a análise de políticas públicas permeia por um constructo social e de pesquisa, para além de uma abordagem sequencial. Destaca-se ainda a abordagem cognitiva, além da análise da gênese da ação pública, quanto a sua problematização, inserção na agenda da ação política, atuação de atores e redes de politicas públicas, racionalidade e irracionalidade da ação pública. (MULLER, SUREL, 2002)

A condicionante, quanto à emergência de um problema e sua eventual colocação na agenda, depende de uma interação inicial de diversos elementos e atores por ocasião de um acontecimento desencadeador. Para tanto, na presente abordagem, se acentua os direitos humanos como elemento central e elo norteador na democratização de políticas publica, através da ampliação de espaços para novos saberes e ativa participação cidadã, individualmente ou de forma organizada. 


\section{PARTICIPAÇÃO CIDAdÃ NAS DECISÕES DE POLÍTICAS PÚBLICAS: UMA NOVA ORDEM DEMOCRÁTICA}

As políticas públicas devem ser compreendidas como um conjunto de decisões e ações, cujo resultado dessas interações estruturadas de forma repetidas entre diferentes atores públicos e privados, implicam na solução para um problema politicamente definido como público. (SUBIRATS, 2012)

Nesse contexto destaca-se a relevância de analisar os diferentes tipos de atores envolvidos em uma política pública, como: os empíricos (caracterizados tanto por um como por vários indivíduos, pessoas jurídicas ou grupo social, que devem atuar com homogeneidade interna sobre os valores e interesses que definam seus objetivos) e os atores intencionais (motivados por uma maximização de sua utilidade tanto material como abstrata). (SUBIRATS, 2012)

Vinculados a importância dos atores em uma análise das políticas públicas, faz-se referência ao espaço. Uma política pública é concebida e organizada pelos atores públicos e privados, que assim constituem uma rede complexa de atores e problemas locais e internacionais, tanto horizontais como verticais.

Atores públicos estão vinculados a alguns elementos fundamentais: como da afirmação de uma soberania dos atores públicos, pela presunção do poder coercitivo do Estado; vinculados a organizações administrativas do sistema político administrativo, sendo que as administrações paraestatais podem se revestir de diversas formas:

\footnotetext{
Organizaciones de economía mixta y privada: sociedades locales de promoción económica o de construcción de viviendas, o sociedades de escala estatal; organizaciones privadas: cajas de ahorros, empresas de servicios, etc., siempre y cuando estén bajo el control de actores político-administrativos; organizaciones sociales: fundaciones, entidades sin ánimo de lucro, pero de hecho dependientes de los organismos públicos. (SUBIRATS, 2012, p. 62)
}

Os atores privados também participam da constituição e estruturação do espaço de uma política pública, sem que isso implique em um controle governamental. A participação dos atores de uma política pública traz a perspectiva de uma triangulação de base, assim as autoridades político-administrativas, atores públicos, atores privados como grupos-objetivo e os beneficiários finais, constituem os três polos deste triângulo. (SUBIRATS, 2012) 
Nesta relação, destaca-se a importância de todos esses atores estarem atentos e cooperarem, independentes dos interesses intermediários, na construção de políticas públicas que novamente colocam o ser humano no centro do processo.

$\mathrm{O}$ índice de pessoas a margem da sociedade no mundo é enorme, tem-se dados de que um bilhão de pessoas tentam sobreviver com menos de um dólar por dia. Schmidt destaca em tal definição as regiões onde se encontram estes excluídos da sociedade:

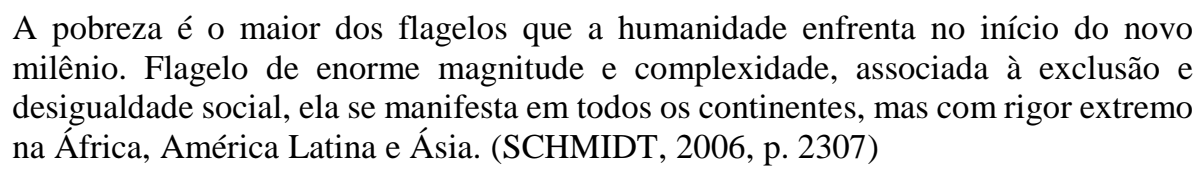

Ao se falar de pobreza, precisa-se ter o cuidado para diferenciá-la da exclusão social, pois a pessoa pode ser pobre sem estar excluída. O termo pobreza tem um elemento histórico mais enraizado, é algo mais antigo, a exclusão, por sua vez, referem-se às várias outras formas de discriminação.

Estas outras formas de discriminação que precisam ser levados em conta pelas políticas públicas e os direitos humanos, necessita pautar-se na importância da compreensão e descrição do capital social.

Ao utilizar o termo capital social, não se tem por pretensão a definição dada pelo direito comercial ou demais campos do direito, mas o destacado na seguinte definição: “Conjunto de redes, relações e normas que facilitam ações coordenadas na resolução de problemas coletivos e que proporcionam recursos que habilitam os participantes a acessarem bens, serviços e outras formas de capital.” (SCHMIDT, 2006, p. 1760)

A presente definição, apesar de ser clara, carrega consigo uma tipologia muito ampla, provocando a necessidade de uma classificação mais específica. Assume-se, portanto, esses três tipos: bonding, bridging e linking, que levam em conta as formas de valores que abrangem os laços familiares, grupais e sociais, sucessivamente.

Tendo por base esses três tipos, percebe-se que capital social não se restringe a determinada classe ou grupo, pobre ou rico, todos têm capital social. O problema está no tipo de capital social, pois enquanto o pobre, com sua baixa auto-estima, se reduz a um capital social envolvendo a família e os vizinhos, o rico engloba um aspecto mais social e coletivo, seu contato com as mais diversas realidades e situações sociais são muito mais amplas.

Não se pretende, a partir de tal perspectiva perder os valores locais para assim desenvolver os valores sociais mais universais, através do fortalecimento do capital social dos 
pobres. Pelo contrário, o que as política públicas precisam ter como referencial é o favorecimento de políticas sociais locais, em vista do fortalecimento local, para então a abertura ao capital social maior. Unindo-se políticas sociais e capital social, têm-se dois dos elementos necessários para a formação de uma sociedade mais sociável e humana.

Os desafios apresentados para o presente momento histórico têm em si um desejo do resgate dos menos favorecidos, para que recebam o necessário e sintam-se pessoas com dignidade. Alimento para o seu dia a dia; educação para o seu presente e futuro; proteção contra as doenças mais contagiosas; combate ao racismo e discriminação pelo sexo; e políticas públicas que buscam proteger o meio ambiente e favorecer pessoas do campo ou da cidade, este é o caminho.

O reconhecimento do capital social em todos os seres humanos é um primeiro passo para dar esse avanço cultural e social, para a valorização de todas as classes sociais e seu capital social.

Jessé de Souza, ao apresentar as classes sociais brasileira, de uma forma crítica, mas relevante, destaca a elite, a classe média, a classe trabalhadora semiqualificada e a ralé de novos escravos. Ele descreve, além das classes, a existência do capital social que pode ser compreendido em suas três formas: o capital econômico, o capital cultural e o capital de relações interpessoais, neste destaca que "Advogados, economistas, publicitários, artistas, administradores, contadores, e assim por diante são, em sua esmagadora maioria, especialistas desse capital cultural valorizado que caracteriza a classe média" (SOUZA, 2017, p. 85)

A forma mais adequada de reconhecer o capital social dos menos favorecidos e aplicar políticas sociais que venham favorecer a tais classes discriminadas é fortalecer políticas públicas que possibilitem o diálogo, a participação e a compreensão clara da sociedade brasileira. No contexto social brasileiro, as políticas sociais mais destacadas são:

Atualmente, as principais políticas sociais em andamento são as voltadas ao combate
à pobreza e à fome; à universalização e à qualificação da educação; à geração de
emprego e renda para os mais pobres; à ampliação e à melhoria dos serviços de saúde;
ao combate às desigualdades socioeconômicas e também às provenientes de raça e
gênero. São, em resumo, políticas focadas na elevação da qualidade de vida dos
brasileiros, especialmente daqueles em situação de vulnerabilidade social. (IPEA,
2010, p. 17)

Essas políticas sociais não foram escolhidas aleatoriamente, ou baseadas em interesses pessoais, são objetivos traçados a nível mundial, assumido por diversos países. Os objetivos têm por destaque: erradicar a extrema pobreza e a fome, universalizar a educação primária, promover a igualdade entre os sexos e a autonomia das mulheres, reduzir a mortalidade na 
infância, melhorar a saúde materna, combater o HIV, a malária e outras doenças, garantir a sustentabilidade ambiental e estabelecer uma parceria mundial para o desenvolvimento.

Implementação de políticas públicas de resgate da dignidade humana dos que são discriminados das mais diversas formas, é o passo adequado para se ter uma sociedade mais humana, com direitos humanos positivados e vividos. Constantemente percebem-se críticas que rotulam os menos favorecidos, pouco se tem visto, por parte dos críticos, de iniciativas para a valorização do capital social dos discriminados.

A modernidade foi criando ao longo do tempo o que se pode chamar de uma cidadania apática, ocupada com interesses pessoais mais do que coletivos, tendo dificuldade de conceder parte deste tempo ao interesse público/comunitário, chegando a configurar a cidadania ativa como um desvalor, na medida em que ameaça as estruturas de poder constituídas nas formas tradicionais de representação políticas existentes. (LEAL, 2011)

Precisa-se crescer em educação, cidadania, políticas de conscientização da valorização do indivíduo, na implementação de políticas públicas adequadas e localizadas ao meio em que o cidadão se encontra. Nesse sentido o paradigma da democracia deliberativa redefine o próprio estado democrático de direito através do conceito de sociedade democrática de direito, nas esferas públicas e sociedade civil ativa, tomando a ordem constitucional instituída como parâmetro de convívio social.

Os processos de deliberação precisam observar alguns requisitos, como: a participação na deliberação, a qual deve ser regulada por normas de igualdade e simetria; do amplo direito de questionar os tópicos fixados no diálogo; e a perspectiva do direito de introduzir argumentos. (LEAL, 2011)

Para além de um estatismo ou privativismo, deve-se buscar o fortalecimento de um equilíbrio entre estado-comunidade-mercado, como nova perspectiva democratica, através da cooperação entre entes estatais e sociedade. Ponto em que se percebe a importância de um cidadão participativa e atuante, que pode ser ainda mais eficaz, se estiver organizado comunitariamente, por vias leais e próprias. 


\section{O TERCEIRO SETOR NA CONSTRUÇÃO DE UMA NOVA ORDEM DE POLÍTICAS PÚBLICAS: UM OLHAR DESDE OS DIREITOS HUMANOS}

A palavra direitos humanos é um termo de dimensão e proporção universal, devidamente aceito pela maioria da população e organizações sociais. Ela foi uma bandeira levantada por revoluções, reformas governamentais e conquistas significativas nas muitas sociedades civis.

A revolução francesa, por exemplo, apesar de também ser conduzido por interesses da classe burguesa, conseguiu, com seu olhar libertador e a bandeira da igualdade, não mais se deixar governar por monarcas, mas ter no próprio cidadão a palavra do seu governo, respeitando a sua dignidade.

O fruto primeiro produzido pelos revolucionais foi a formulação da constituição e a promulgação dos direitos humanos. Neles se encontra o suporte necessário para estruturar o pensar sobre o estado, homem e a sociedade. Tal foi a importância da presente estruturação que ainda hoje eles são lembrados e acentuados.

Os princípios das declarações foram tão revolucionários na história das ideias quanto
o foram às revoluções na história da política. Podemos acompanhar os temas, as
preocupações e os temores da modernidade na trajetória dos direitos dos homens. Se
a modernidade é a época do sujeito, os direitos humanos coloriram o mundo à imagem
e semelhança do indivíduo. O impacto da Declaração Francesa, em particular, foi
profundo. (DOUZINAS, 2009. p. 99)

Após a segunda guerra mundial, os países aliados, mesmo tendo alcançado uma vitória esmagadora, não se contiveram perante os massacres realizados nos campos de concentração. Perceberam a necessidade de apresentar normas adequadas para prevenir novas atrocidades à humanidade para todos os povos. Retomam-se os direitos declarados na Revolução Francesa e se faz devida adequação para que estes sejam apresentados para toda humanidade, conforme desta Gorczevski:

\footnotetext{
Já nos primeiros artigos da Declaração percebe-se a retomada dos ideais da Revolução Francesa, os valores supremos da igualdade, da liberdade e da fraternidade entre os homens são agora apresentados no âmbito universal. E, sabiamente dispôs, na introdução, que a transformação deste ideal comum em direitos efetivos far-se-á progressivamente, pela adoção, no plano nacional e internacional, de medidas de ensino e de educação. (GORCZEVSKI, 2009. p. 153)
}

Esses dois fatos significativos e tantos outros testemunhos pessoais de lutas contra a discriminação e o racismo, levam a conclusão de que o homem possuidor de determinada base 
de instrução moral, que valoriza a sociedade e o próximo, aceita os direitos humanos e os defende, se esses não forem respeitados.

O problema encontra-se no passo seguinte, no concretizar o determinado por leis, acordos, decretos ou tratados. Pois perante os direitos humanos, não basta aceitar as normas positivadas, não basta levantar a bandeira, não basta ensiná-los nas varias entidades de ensino. As políticas públicas e a participação ativa e democrática do cidadão apresentam-se como meios adequados na efetivação de tais direitos.

Por vezes, esse cidadão individualmente não encontra suporte necessário para uma atuação efetiva, conforme lhe é permitido num estado democrático de direito. Como suporte e referencial para a maior concretização de políticas públicas, com a participação do cidadão, destaca-se a importância do terceiro setor, que se encontra entre o público e o privado, entre o mercado e o estado, fortalecido no valor da comunidade, do ser comunitário.

O pensamento comunitário se fundamenta na ideia de cooperação, na proximidade e relação entre cidadãos, em seus objetivos e propósitos:

Comunitário deriva do latim communis (comum) e comunitas (comunidade). Comunidade designa a forma de vida social caracterizada por relações personalizadas, de coesão social, de compromisso moral e de continuidade no tempo, distinta das formas marcadas pela impessoalidade, anonimato e contratualidade. (SCHMIDT, 2017, p. 77)

O terceiro setor ou terceira via, muito vinculada ao pensamento comunitarista, que favorece a participação e organização do cidadão, num estado democrático de direito, se define como:

Terceiro setor é aqui assumido como aquele que compreende as organizações criadas e mantidas pelos cidadãos para atender necessidades e anseios coletivos, sem cunho mercantil voltado ao lucro individual, nem imerso no aparato estatal. É o conjunto de organizações criadas e mantidas pela sociedade civil (ou comunidade), que proporcionam bens e serviços de interesse comum e cujos resultados são apropriados coletivamente. É, portanto mais vasto que as chamadas organizações sem fins lucrativos, cooperativas, sindicatos e outras organizações da sociedade civil. O terceiro setor é distinto do setor privado: não deve ser analisado como um mero subproduto que resulta das falhas do mercado e do Estado, nas palavras de Vasco Almeira (2011), e sim um elemento central na estrutura de governação das sociedades contemporâneas. (SCHMIDT, 2017, p. 119-120)

Essa terceira via ou via comunitária, é uma alternativa relevante para a aplicação e implementação de políticas públicas, com valorização do capital social e participação do cidadão, em vista do reconhecimento dos direitos humanos e da sua dignidade, pois está intimamente ligado a estes valores. 
Nessa perspectiva, conforme os dados apresentados anteriormente é louvável, quando se percebe um trabalho realizado pela sociedade e pelo governo no combate a mortalidade infantil e a melhoria da saúde, o que também inclui o combate a doenças. Sabe-se, contudo, que muitas dessas conquistas se devem a trabalhos de grupos localizados, movimentos e organizações que unidos aos governos favoreceram a diminuição dos números negativos.

Outro dado significativo e exemplificativo é o espaço conquistado pela mulher no mercado de trabalho, contudo, como esse processo é moroso e contínuo, se percebe que a própria violência doméstica é uma realidade que ainda preocupa. Políticas públicas mais próximas da comunidade, delegacias e orientações de âmbito mais familiar seriam mais adequadas e chegariam a resultados mais precisos.

A proteção do meio ambiente, água, esgoto, flora e fauna são políticas públicas que ainda não estão totalmente amadurecidas. Sabe-se que o desmatamento diminuiu, mas a compreensão do cidadão ainda não conseguiu chegar a valorizar a necessidade da proteção no planeta. Ainda faltam políticas de conscientização, para que a proteção do meio ambiente, o cuidado com os esgotos, flora e fauna não sejam motivados por ameaças de punições, mas pelo próprio desejo do homem favorecer o ser humano pela sua dignidade, pelo seu valor.

Das políticas públicas atuais, presentes no estado brasileiro, destaca-se a importância imediata de políticas de sustentabilidade, contudo faz-se necessário o fortalecimento de políticas de desenvolvimento, aprendizagem e formação, com fundamentos na própria comunidade. E para uma participação mais efetiva e consciente do cidadão, observa-se a necessidade de analisar a identidade e a relação dos seres humanos entre si e com seu contexto social, fortalecendo a compreensão de que a pessoa não deve ser vista como o meio para determinada realização, mas fim em si mesmo.

As comunidades são o ambiente das relações Eu-Tu (ou Eu-Nós), as relações baseadas
em fins; enquanto o mercado é o reino das relações Eu-Isso, relações baseadas em
meios. Para Etzioni, a boa sociedade é definida como aquela em que as pessoas se
tratam como fins, e não como meios, concepção apoiada na formulação de Martin
Buber, filósofo que desenvolveu uma profunda filosofia da relação e do diálogo, cujo
núcleo é a distinção entre as palavras-princípio Eu-Tu e Eu-Isso. (SCHMIDT, 2017,
p. 175)

Percebendo a importância do pensamento de Amitai Etzioni, como matriz teórica do presente item, se faz referência a alguns elementos que são apresentados por ele, em vista da construção da "boa sociedade", em que o cidadão participativo, comunidade, mercado e estado 
percebem o seu espaço e valor, proporcionando uma atuação mútua, na implementação de políticas públicas que têm como referência os direitos humanos.

Um ponto relevante destacado pelo autor é o equilíbrio e a junção do estado, o setor privado (mercado) e a comunidade:

La buena sociedad es una sociedad equilibrada con tres puntos de apoyo: el estado, la comunidad y el sector privado (el mercado). Es necesario que los tres se coordinen (en el mundo occidental el déficit más grande es el comunitario) mediante un acuerdo del - bagaje moral de la sociedad. (ETZIONI, 2001. p. 10)

Nações onde a economia, o mercado são supervalorizados, como por exemplo, os Estados Unidos da América, o estado deixa de ter a sua participação direta na relação do Eu$\mathrm{Tu}$, ou nos países onde o estado tem um poder centralizador, a relação entre as pessoas fica prejudicada. Faz se necessário a presença de um estado forte, de um mercado com fornecimento do necessário, mas um desenvolvimento localizado, comunitário, para que a pessoa cresça junto com seu estado, sua nação e o próprio setor privado.

A terceira via terceiro setor ou visão comunitarista conforme ETZIONI, não se caracteriza como sendo um partido político ou visão política, ela é uma alternativa política encontrada entre o mercado e o estado, onde a comunidade exerce seu papel fundamental na participação e organização de políticas públicas, em vista do desenvolvimento da pessoa humana, bem localizada e definida.

A relevância da comunidade para a boa sociedade - um tema ignorado por grande parte da filosofia política - é a ideia central do comunitarismo. Enquanto os liberais acreditam nas virtudes do livre mercado e os social-conservadores nas virtudes do bom Estado, os comunitaristas creem nas virtudes da boa sociedade (Etzioni, 2004). Afinal o papel político da comunidade na sua relação com o Estado e o mercado requer que se recupere a noção de que historicamente comunidade é muito anterior às outras esferas. (SHCMIDT, 2017, p. 116)

O estado tem a sua importância insubstituível nesse processo, tanto que o compromisso com a institucionalização da democracia, a indução do desenvolvimento sustentável, coordenação e articulação de políticas públicas, a sintonia entre políticas sociais e políticas econômicas, a regulação econômica e arbitragem de conflitos, a reforma das estruturas estatais, coordenação das ações de proteção ambiental, implementação de políticas de justiça comunitárias, são algumas áreas de atuação específica do estado.

Por sua vez, o mercado ciente do seu valor, uma vez regulado, é reconhecido pelo estado e pela sociedade por proporcionar o desenvolvimento social, além de ser o melhor motor 
para a produção de bens e serviços, viabilizando as próprias políticas públicas de inclusão social.

\begin{abstract}
A boa sociedade é caracterizada pelo tripé Estado-comunidade-mercado em equilíbrio; esferas complementares que devem atuar sinergicamente, uma vez que cada qual tem uma contribuição própria e insubstituível, que não pode ser adequadamente suprida por outra. A terceira via etzioniana considera que o Estado tem entre suas principais atribuições a segurança e a saúde pública, a regulação do mercado e a proteção ambiental. O mercado é tido como o melhor motor para a produção de bens e serviços, de geração de oportunidades de trabalho, de emprego e de progresso econômico; enquanto que a comunidade é a melhor alternativa para a prestação de uma série de serviços sociais e indispensável para a difusão de valores morais compartilhados (Etzioni, 1999; 2001a; 2007). (SCHMIDT, 2017, p. 189)
\end{abstract}

Na compreensão de Etzioni, na busca pelo equilíbrio entre mercado e estado, precisa se ter a atenção especial para o ser humano, tanto que independentemente da sua condição social e econômica, ele merece e deve ter o mínimo necessário para viver. Esse mínimo necessário dispensa qualquer ação de trabalho, pois mercado, estado e comunidade, para serem humanizadores e se desenvolverem dignamente, devem oferecer essa condição mínima para todo ser humano.

O autor foge da simples institucionalização das pessoas, onde elas são usadas como instrumentos do estado ou do mercado, reconhecendo o valor da própria dignidade humana. Para ETZIONI o lugar que mais acontece esse reconhecimento, é na comunidade:

El principio ético de que la gente debe ser tratada como un fin y no como un medio está ampliamente reconocido. Bastante menos aceptada resulta la significativa observación sociológica de que es en la comunidades, y en el estado o el mercado, donde este principio está mejor institucionalizado. (ETZIONI, 2001. p. 17)

O ponto de partida ou berço da visão comunitária e terceiro setor, para Etzioni, encontra-se nos escritos bíblicos do Antigo Testamento e do Novo testamento, onde a cooperação e a comunidade tinham o seu valor fundamental. Tal visão é acompanhada pela história dos muçulmanos e demais povos antigos, que buscavam uma harmonia de estruturação e vivência.

O termo comunidade, conforme Etzioni, também precisa ser compreendido de uma forma mais ampla. Na forma tradicional comunidade se refere a família e grupos fechados, em que os aspectos da afetividade e a cultura compartilhada eram as únicas chaves de leitura. Atualmente comunidade pode ser definida como grupo profissional, sindicatos, movimentos de lutas e protestos, neles se diminuem os laços afetivos e se fortalecem os objetivos comuns.

Comunidade é uma combinação de dois elementos: (a) Uma rede de relações carregadas de afeto entre um grupo de indivíduos, relações que frequentemente se 
cruzam e se reforçam umas às outras (em vez de tão somente relações individuais, uma a uma ou encadeadas). (b) Uma medida de compromisso com um conjunto de valores compartilhados, normas e significados, e uma história e identidade compartilhadas - em resumo, com uma cultura particular (ETZIONI, 2001b, p. 142143)

Observa-se que todos os pontos destacados contribuem para reforçar a percepção de que para existirem políticas públicas cada vez mais eficazes, o envolvimento e a participação da comunidade local organizada, dando voz ao cidadão, é fundamental, além de fortalecer a própria identidade de um estado democrático de direito. Por exemplo: na aplicação de projetos de assistência social a crianças carentes em bairros de baixa renda, percebe-se que os recursos financeiros e políticas públicas apáticas a participação do cidadão local, por si só, não conseguem resgatar a dignidade dos atendidos de uma forma integral.

Políticas públicas com participação do terceiro setor, não significa dar à comunidade a total responsabilidade de desenvolver os projetos, existem elementos que não podem fugir da alçada do estado e do setor privado. Evitando extremos, a cooperação e a participação do cidadão organizado, em todo processo das políticas públicas, tende a produzir melhores resultados, em vista da efetivação dos direitos humanos, que lhes são próprios.

\section{CONCLUSÃO}

Conforme a estruturação do tema proposto, caminhando entre a teoria e apresentação de alguns exemplos, reconhecendo o valor das políticas públicas, do capital social, do cidadão e do terceiro setor no contexto atual, acredita-se que, entre desafios e perspectivas, sonhos e realidades possíveis, apresentou-se mais uma contribuição para a construção dos direitos humanos, numa caminhada cada vez mais universal, sem deixar de valorizar o elemento local. Ainda em vista desse mesmo processo, das inúmeras particularidades locais e sociais abordadas, fazem-se ainda algumas ponderações.

Toda definição de problema, formulação, implementação e avaliação de política pública mais localizada, deve ter o cuidado de estar em consonância com a comunidade local. Políticas sem o estudo de fatores sociais e culturais locais, e sem a participação efetiva da comunidade local, tendem a não produzirem resultados de qualidade, podendo inclusive prejudicar a própria sociedade local.

Como contraponto, destaca-se que apesar da importância do cidadão e da comunidade, por vezes o poder da comunidade prejudica o reconhecimento de direitos humanos, dados inclusive em proporções de importância universais. Por exemplo, mutação sexual feminina, 
apresentada como costume em alguns grupos sociais, fere a dignidade humana e não deve ser aceito por uma sociedade considerada humanizada e humanizadora.

Quando se acentua o valor do ser humano e sua centralidade, tendo como elemento construtor o terceiro setor, se atribui a cada sujeito direitos e deveres, em vista do bem comum. Por exemplo: do estudante se espera serviços comunitários, do idoso participação; do enfermo o cuidado com epidemias.

Independente da participação de todos e cada um, o mínimo necessário deve ser dado para todos, mesmo os embriagados, drogados, aqueles que não querem melhorar sua situação. Todo recurso, com as políticas públicas precisa ensinar as pessoas a desejarem sair da situação desconfortável e buscar algo melhor, mas existem aqueles que receberão os recursos por toda a vida, desprezá-los? Não, pois continuam sendo humanos.

Por fim, nesse processo de implementação de políticas públicas e relação entre terceiro setor, estado e mercado, funções específicas são próprias e intransferíveis, por exemplo: segurança pública é responsabilidade própria do estado. Mesmo assim, cooperação e centralidade no ser humano, na estruturação e implementação de políticas públicas, proporcionam uma identidade comum e favorecem a participação efetiva do cidadão.

\section{REFERÊNCIAS}

BALDI, César Augusto. Direitos humanos na sociedade cosmopolita. Rio de Janeiro: Renovar, 2004.

BARRETTO, Vicente de Paulo (coord.). Dicionário de Filosofia do Direito. São Leopoldo: Unisinos, 2006.

BIELEFELDT, Heiner. Filosofia dos direitos humanos. São Leopoldo: Unisinos, 1998.

DOUZINAS, Costas. O fim dos Direitos Humanos. São Leopoldo: Editora Unisinos, 2009.

ETZIONI, Amitai. La tercera via.Madrid: Editorial Trotta, 2001.

FARIA, José Eduardo. O futuro dos direitos humanos após a globalização econômica.In: O cinquentenário da declaração universal dos direitos humanos. São Paulo: Edusp, 1999.

FERNÁNDES-LARGO, Antônio Osuna. Pilares para a fundamentação dos direitos humanos. Santa Cruz do Sul: EDUNISC, 2006.

GORCZEVSKI, Clovis. Direitos humanos educação e cidadania: Conhecer, educar, praticar. Santa Cruz do Sul: EDUNISC, 2009. 
IPEA. Objetivos de desenvolvimento do milênio. Relatório Nacional de Acompanhamento. Brasília: Ipea, 2010.

LEAL, Rogério Gesta. A democracia deliberativa como nova matriz de gestão pública: alguns estudos de casos. Santa Cruz do Sul: EDUNISC, 2011.

MULLER, Pierre; SUREL, Yves. A análise das políticas públicas. Pelotas: Educat, 2002.

SCHMIDT, João Pedro. Exclusão, inclusão e capital social: o capital social nas ações de inclusão. In: REIS, J. R.; LEAL, R. G. (org.) Direitos sociais e políticas públicas. Tomo 6. Santa Cruz do Sul, EDUNISC, 2006.

Para entender as políticas públicas: aspectos conceituais e metodológicos. In: REIS, J. R.; LEAL, R. G. (org.) Direitos sociais e políticas públicas: desafios contemporâneos. Tomo 8. Santa Cruz do Sul, EDUNISC, 2008.

Universidades comunitárias e terceiro setor: fundamentos comunitaristas da cooperação em políticas públicas. Santa Cruz do Sul: EDUNISC, 2017.

SOUZA, Jessé. A elite do atraso da escravidão à lavo jato. Rio de Janeiro: Leya, 2017.

SUBIRATS, Joan et al. Análisis y gestión de políticas públicas. Barcelona: Planeta, 2012. 